\title{
Allosteric Agonism of $\alpha 7$ Nicotinic Acetylcholine Receptors: Receptor Modulation Outside the Orthosteric Site ${ }^{\mathrm{s}}$
}

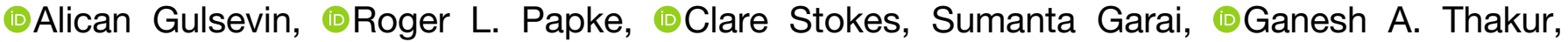 \\ (1) Marta Quadri, and Nicole A. Horenstein
}

Departments of Chemistry (A.G., M.Q., N.A.H.) and Pharmacology and Therapeutics (R.L.P, C.S., M.Q.), University of Florida, Gainesville, Florida; and Department of Pharmaceutical Sciences, School of Pharmacy, Bouvé College of Health Sciences, Northeastern University, Boston, Massachusetts (S.G., G.A.T.)

Received January 15, 2019; accepted March 24, 2019

\section{ABSTRACT}

Nicotinic acetylcholine receptors (nAChRs) are members of the Cys-loop superfamily of ligand-gated ion channels. Typically, channel activation follows the binding of agonists to the orthosteric binding sites of the receptor. $\alpha 7 \mathrm{nAChRs}$ have a very low probability of channel activation, which can be reversed by the binding of $\alpha 7$ selective positive allosteric modulators (PAMs) to putative sites within the transmembrane domains. Although typical PAMs, like PNU-120596, require coapplication of an orthosteric agonist to produce large channel activations, some, like GAT107 and B-973B [(S)-3-(3,4-difluorophenyl)-N-(1-(6-(4(pyridin-2-yl)piperazin-1-yl)pyrazin-2-yl)ethyl)propanamide], are characterized as allosteric activating PAMs, which also bind to an allosteric activation (AA) site in the extracellular domain and activate the $\alpha 7$ ion channel by themselves. We had previously characterized $N, N$-diethyl- $N^{\prime}$-phenylpiperazine analogs with various functions. In this work, we docked members of this family to a homology model of the $\alpha 7$ receptor extracellular domain. The compound 1,1-diethyl-4(naphthalene-2-yl)piperazin1-ium (2NDEP) a weak partial agonist, showed particularly favorable docking and binding energies at the putative $A A$ site of the receptor. We hypothesized that 2 NDEP could couple with PAMs through the AA site. This hypothesis was tested with the $\alpha 7$ mutant C190A, which is not activated by orthosteric agonists but is effectively activated by GAT107. The results showed that 2NDEP acts as an allosteric agonist of $\alpha 7$ C190A when coapplied with the PAM PNU-120596. Also, the allosteric activity was nearly abolished upon coapplication with the AA site-selective antagonist 2,3,5,6MP-TQS (cis-trans-4-(2,3,5,6-tetramethylphenyl)3a,4,5,9b-tetrahydro-3H-cyclopenta[c]quinoline-8-sulfonamide), consistent with AA site involvement. Overall, our findings show a novel mode of agonism through an allosteric site in the extracellular domain of $\alpha 7 \mathrm{nAChR}$.

\section{Introduction}

The high expression of the $\alpha 7$ type nicotinic acetylcholine receptor (nAChR) in brain regions such as the hippocampus commends it as a potential target for cognitive disorders such as Alzheimer's disease, and schizophrenia. More recently, its essential role in the cholinergic antiinflammatory pathway (CAP) has suggested that it may also provide a path for the treatment of inflammatory diseases and neuropathic pain. However, the unique properties of $\alpha 7 \mathrm{nAChR}$ continue to present puzzles, challenges, and opportunities.

The first well-studied nAChR was that of the neuromuscular junction. A pentamer of $\alpha 1, \beta 1, \gamma$, and either $\delta$ or $\varepsilon$ subunits, with two $\alpha 1$ subunits per pentamer, muscle-type nAChRs

\footnotetext{
This work was supported by NIH grant [GM57481].

https://doi.org/10.1124/mol.119.115758.

S This article has supplemental material available at molpharm.aspetjournals.org.
}

function efficiently as ligand-gated ion channels mediating fast synaptic transmission (for review, see Papke, 2014). The nAChR of autonomic ganglia, containing varying assemblies of $\alpha 3, \beta 2, \beta 4, \alpha 5$, and possibly other subunits, also are effective mediators of synaptic transmission. Although heteromeric assemblies of nAChR subunits expressed in the brain, such as $\alpha 4, \beta 2, \alpha 5, \alpha 6$, and $\beta 3$, are capable of synapticlike activation in response to the rapid application of high concentrations of ACh, the slower, more diffuse delivery of ACh in the brain is consistent with neuromodulatory functions of these receptors in vivo. For all of these heteromeric nAChR subtypes, ion channel function relies largely on the binding of ACh or other agonists to the two orthosteric ligand binding domains configured at the interface between $\alpha$ and non- $\alpha$ subunits.

$\alpha 7 \mathrm{nAChRs}$, though, function most effectively as homomeric pentamers with five $\alpha$ subunits, and hence potentially five agonist binding sites at each $\alpha-\alpha$ interface. However, the

ABBREVIATIONS: AA, allosteric activation; ACh, acetylcholine; $\alpha 7 \mathrm{AChBP}$, humanized chimeric acetylcholine binding protein; ago-PAM, allosteric activating positive allosteric modulator; CAP, cholinergic anti-inflammatory pathway; diEPP, $N, N$-diethyl- $N$ '-phenylpiperazine; ECD, extracellular domain; GAT107, ((3aR,4S,9bS)-4-(4-bromophenyl)-3a,4,5,9b-tetrahydro-3H-cyclopenta[c]quinoline-8-sulfonamide); MD, molecular dynamics; MMPBSA, molecular mechanics Poisson-Boltzmann surface area; nAChR, nicotinic acetylcholine receptor; 2NDEP, 1,1-diethyl-4(naphthalene-2yl)piperazin-1-ium; NOAR, nonorthosterically activatible receptor; OA, orthosteric activation; PAM, positive allosteric modulator; PNU-120596 (1-(5chloro-2, 4-dimethoxyphenyl)-3- (5-methylisoxazol-3-yl)-urea); 2,3,5,6MP-TQS, cis-trans-4-(2,3,5,6-tetramethylphenyl)-3a,4,5,9b-tetrahydro-3Hcyclopenta[c]quinoline-8-sulfonamide; TMD, transmembrane domain; WT, wild type. 
binding of agonist to the orthosteric activation (OA) sites of $\alpha 7 \mathrm{nAChR}$ couples rather ineffectively to channel activation, and high levels of agonist binding primarily induce nonconducting (i.e., desensitized) conformations. Despite these limitations, as noted above, $\alpha 7 \mathrm{nAChRs}$ have been identified as essential activators of CAP, a sort of metabotropic cascade mediated by immune cells, for which $\alpha 7$ channel activation seems unimportant. This is consistent with the data that show that silent agonists, which are partial agonists with little or no efficacy for channel activation in neuronal cells or in heterologous expression systems, are among the best activators of CAP (Horenstein and Papke, 2017).

The discovery of $\alpha 7$ selective positive allosteric modulators (PAMs) has led to important insights into the conformational dynamics of $\alpha 7 \mathrm{nAChRs}$. The most effective PAMs bind within the transmembrane domain (TMD) of the receptor and destabilize one or more of the nonconducting states induced by the binding of agonists or silent agonists, resulting in protracted bursts of channel activation in just a small fraction of the receptors when an orthosteric agonist is also bound. Although conventional PAMs like PNU-120596 and 2,3,5,6MP-TQS require the agonist induction of the PAM-sensitive desensitized states, allosteric activating PAMs (ago-PAMs), like GAT107 (Fig. 1) and B-973B [(S)-3(3,4-difluorophenyl)-N-(1-(6-(4-(pyridin-2-yl)piperazin-1-yl)pyrazin-2-yl)ethyl)propanamide] (Gill et al., 2011; Thakur et al., 2013; Post-Munson et al., 2017), have also been identified. Ago-PAMs induce channel activation without orthosteric agonist-induced conformational effects and can indeed activate large currents in receptors with mutations in the orthosteric binding interface that disable orthosteric agonist binding and channel activation [i.e., nonorthosterically activatible receptors (NOARs)]. Several lines of evidence have indicated that these ago-PAMs produce direct allosteric activation (AA) by acting at both the conventional transmembrane PAM site and an additional allosteric site in the extracellular domain (ECD) of the receptor, including inhibition by molecules such as 2,3,5,6MP-TQS (Fig. 1) that do not affect OA (Gill-Thind et al., 2015; Horenstein et al., 2016). This suggested the hypothesis that alternative small ligands might be identified that would bind to such an allosteric agonist binding site to produce PAM-dependent activation.

As noted above, we have previously identified silent agonists as PAM-dependent activators that hypothetically worked through the orthosteric agonist binding site, including a large structurally diverse group of $N, N$-diethyl- $N^{\prime}$-phenylpiperazine (diEPP)-related compounds (Quadri et al., 2016). We conducted in silico analyses to test the hypothesis that one or more of these analogs might alternatively bind preferentially to the AA site to produce PAM-dependent activation. We confirmed that 1,1-diethyl-4(naphthalene-2-yl)piperazin1-ium (2NDEP) (Fig. 1), a compound that showed particularly favorable docking and binding energies at the putative AA site of the receptor, produced PAM-dependent activation that did not depend on binding to a functional orthosteric binding site. These results confirm the presence of a novel AA site on $\alpha 7$ that can be selectively targeted. Developing new drugs for this site may also provide a new approach for the control of CAP and associated indications related to neuropathic pain and inflammation.

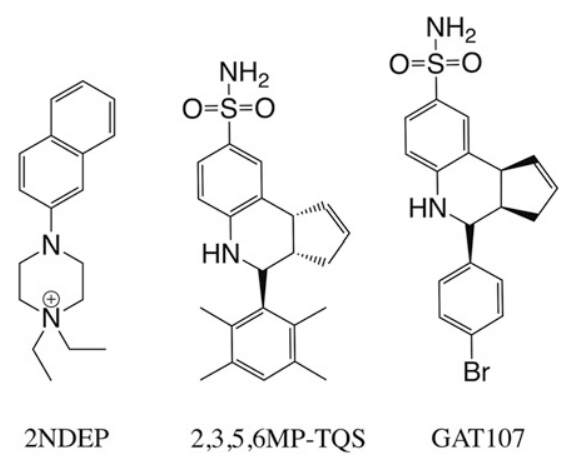

Fig. 1. Structures of the three molecules used for the docking and MD and electrophysiology studies: the putative allosteric agonist 2NDEP, AA siteselective antagonist 2,3,5,6MP-TQS, and ago-PAM GAT107.

\section{Materials and Methods}

\section{Computational}

A full description of computational methodology is provided in the Supplemental Material. Briefly, all compounds that were used in docking studies had their structures optimized and atomic parameters calculated with the Gaussian09 and antechamber programs (Wang et al., 2004, 2006; Frisch et al., 2016). The $\alpha 7 \mathrm{nAChR}$ homology model (Quadri et al., 2019) used for docking was created with Prime (Schrödinger, LLC, Cambridge, MA) (Jacobson et al., 2002), using as a template the crystal structure for the humanized acetylcholine (ACh) binding protein (Protein Data Bank identification number 3SQ6) (Li et al., 2011). The homology model was refined using molecular mechanics and molecular dynamics (MD) within the AMBER 16 suite of programs (AMBER, University of California, San Francisco, San Francisco, CA) (Case et al., 2008).

Docking studies used the GlideXP (Schrödinger, LLC) (Friesner et al., 2006) program within the Schrödinger computational suite. Binding energies were calculated with the molecular mechanics PoissonBoltzmann surface area (MMPBSA) method, within AMBER 16.

\section{Experimental}

Chemicals and Reagents. ACh and buffer chemicals were purchased from Sigma-Aldrich (St. Louis, MO). The diEPP derivative 2NDEP was synthesized in our laboratory as described previously (Quadri et al., 2016). GAT107 and 2,3,5,6MP-TQS were synthesized by G.A.T. (Northeastern University, Boston, MA) after the published procedures (Kulkarni and Thakur, 2013; Thakur et al., 2013; GillThind et al., 2015). PNU-120596 was synthesized in our laboratory (University of Florida, Gainesville, FL) by Dr. Kinga Chojnacka after the published procedure (Hurst et al., 2005).

Heterologous Expression of nAChRs in Xenopus laevis Oocytes. The human $\alpha 7 \mathrm{nAChR}$ clone was obtained from Dr. J. Lindstrom (University of Pennsylvania, Philadelphia, PA). The human RIC-3 (resistance-to-cholinesterase 3) clone was obtained from Dr. M. Treinin (Hebrew University, Jerusalem, Israel) and coinjected with $\alpha 7$ to improve the level and speed of $\alpha 7$ receptor expression without affecting the pharmacological properties of the receptors (Halevi et al., 2003). Subsequent to linearization and purification of the plasmid cDNAs, complementary RNAs were prepared using the Ambion mMESSAGE mMACHINE in vitro RNA Transcription Kit (Thermo Fisher Scientific, Waltham, MA). The $\alpha 7$ C190A mutant was made as previously described with a C116S double mutation to prevent spurious disulfide bond formation with the free cysteine (Papke et al., 2011). The harvested oocytes were treated with $1.4 \mathrm{mg} / \mathrm{ml}$ type 1 collagenase (Worthington Biochemicals, Freehold, NJ) for 2-4 hours at room temperature in calcium-free Barth's solution $(88 \mathrm{mM} \mathrm{NaCl}$, $1 \mathrm{mM} \mathrm{KCl}, 2.38 \mathrm{mM} \mathrm{NaHCO}_{3}, 0.82 \mathrm{mM} \mathrm{MgSO}_{4}, 15 \mathrm{mM}$ HEPES, and $12 \mathrm{mg} / \mathrm{l}$ tetracycline, $\mathrm{pH}$ 7.6) to remove the ovarian tissue and the 
TABLE 1

Effects of allosteric antagonism on WT $\alpha 7$ and $\alpha 7$ C190A

\begin{tabular}{|c|c|c|c|}
\hline & $n$ & Peak & Charge \\
\hline \multicolumn{4}{|l|}{ WT $\alpha 7$ (normalized to $60 \mu \mathrm{M}$ ACh control \pm S.D.) } \\
\hline \multicolumn{4}{|l|}{ Figure 3B } \\
\hline $60 \mu \mathrm{M}$ ACh $+30 \mu \mathrm{M}$ PNU & 8 & $19.2 \pm 22.3$ & $89.0 \pm 50.9$ \\
\hline $60 \mu \mathrm{M} \mathrm{ACh}+30 \mu \mathrm{M}$ PNU $+300 \mu \mathrm{M} 2,3,5,6, \mathrm{MP}-\mathrm{TQS}$ & 5 & $8.8 \pm 1.2^{a}$ & $33.0 \pm 13.4^{*}$ \\
\hline \multicolumn{4}{|l|}{ Figure $3 \mathrm{~B}$} \\
\hline $30 \mu \mathrm{M} 2 \mathrm{NDEP}+30 \mu \mathrm{M}$ PNU & 8 & $5.4 \pm 2.5$ & $10.8 \pm 9.0$ \\
\hline $30 \mu \mathrm{M} 2 \mathrm{NDEP}+30 \mu \mathrm{M}$ PNU $+300 \mu \mathrm{M} 2,3,5,6, \mathrm{MP}-\mathrm{TQS}$ & 8 & $0.28 \pm 0.11^{* * * *}$ & $0.38 \pm 0.11^{* *}$ \\
\hline \multicolumn{4}{|l|}{$\begin{array}{l}30 \mu \mathrm{M} 2 \mathrm{NDEP}+30 \mu \mathrm{MI} P \mathrm{NU}+300 \mu \mathrm{M} 2,3,5,6, \mathrm{MIP}-\mathrm{TQS} \\
\text { Figure } 5 \mathrm{~B}\end{array}$} \\
\hline $100 \mu \mathrm{M} p$-CF3 diEPP + $100 \mu \mathrm{M}$ PNU & 8 & $7.0 \pm 4.8$ & $13.6 \pm 3.1$ \\
\hline $100 \mu \mathrm{M} p$-CF3 diEPP $+100 \mu \mathrm{M}$ PNU $+300 \mu \mathrm{M} 2,3,5,6, \mathrm{MP}-\mathrm{TQS}$ & 7 & $12.3 \pm 6.9^{a}$ & $13.4 \pm 2.9^{a}$ \\
\hline \multicolumn{4}{|l|}{$\alpha 7 \mathrm{C} 190 \mathrm{~A}$ (normalized to $10 \mu \mathrm{M}$ GAT107 \pm S.D.) } \\
\hline \multicolumn{4}{|l|}{ Figure 4B } \\
\hline $100 \mu \mathrm{M} 2 \mathrm{NDEP}+100 \mu \mathrm{M}$ PNU & 7 & $0.91 \pm 0.34$ & $0.74 \pm 0.26$ \\
\hline $100 \mu \mathrm{M} 2 \mathrm{NDEP}+100 \mu \mathrm{M}$ PNU $+300 \mu \mathrm{M} 2,3,5,6, \mathrm{MP}-\mathrm{TQS}$ & 7 & $0.27 \pm 0.18^{* *}$ & $0.21 \pm 0.13^{* *}$ \\
\hline \multicolumn{4}{|l|}{ Figure $5 \mathrm{~B}$} \\
\hline $100 \mu \mathrm{M} p$-CF3 diEPP + $100 \mu \mathrm{M}$ PNU & 8 & $0.28 \pm 0.25$ & $0.11 \pm 0.11$ \\
\hline $100 \mu \mathrm{M} p$-CF3 diEPP + $100 \mu \mathrm{M}$ PNU $+300 \mu \mathrm{M} 2,3,5,6, \mathrm{MP}-\mathrm{TQS}$ & 8 & $0.04 \pm 0.28^{*}$ & $0.01 \pm 0.03^{*}$ \\
\hline
\end{tabular}

follicular layers. Stage V oocytes were subsequently isolated and injected with $50 \mathrm{nl}$ of $5-20 \mathrm{ng}$ nAChR subunit complementary RNA. Oocytes were maintained in Barth's solution with calcium [additional $0.32 \mathrm{mM} \mathrm{Ca}\left(\mathrm{NO}_{3}\right)_{2}$ and $0.41 \mathrm{mM} \mathrm{CaCl} \mathrm{Cl}_{2}$, and recordings were carried out 1-14 days after injection.

Two-Electrode Voltage-Clamp Electrophysiology. Experiments were conducted using OpusXpress 6000A (Molecular Devices, Union City, CA) (Papke and Stokes, 2010). Both the voltage and current electrodes were filled with $3 \mathrm{M} \mathrm{KCl}$. Oocytes were voltage clamped at $-60 \mathrm{mV}$ at room temperature $\left(24^{\circ} \mathrm{C}\right)$. The oocytes were bath perfused with Ringer's solution (115 mM NaCl, $2.5 \mathrm{mM}$ $\mathrm{KCl}, 1.8 \mathrm{mM} \mathrm{CaCl}_{2}, 10 \mathrm{mM}$ HEPES, and $1 \mu \mathrm{M}$ atropine, $\mathrm{pH}$ 7.2) at $2 \mathrm{ml} / \mathrm{min}$. To evaluate the effects of experimental compounds compared with ACh-evoked responses of various nAChR subtypes expressed in oocytes, control responses were defined as the average of two initial applications of ACh made before test applications. Solutions were applied from 96 -well plates via disposable tips. Drug applications were 12 seconds in duration followed by 181-second washout periods. A typical recording for each set of oocytes constituted two initial control applications of ACh, one or more experimental compound applications, and then a follow-up control application of ACh. The control ACh concentration was $60 \mu \mathrm{M}$ for the wild-type (WT) receptor experiments, and the average of independent $10 \mu \mathrm{M}$ GAT107 responses was used as the control for the NOAR experiments. The responses were calculated as both peak current amplitudes and net charges, as previously described (Papke and Porter Papke, 2002), and the averages of the two initial controls were used for normalization purposes. Data were collected at $50 \mathrm{~Hz}$, filtered at $20 \mathrm{~Hz}$, and analyzed by Clampfit version 9.2 or 10.0 (Molecular Devices, San Jose, CA) and Excel (Microsoft, Redmond, WA). Data were expressed as the mean \pm S.E.M. from at least four oocytes for each experiment, unless otherwise stated, and plotted by Kaleidagraph version 4.5.2 (Abelbeck Software, Reading, PA). Multicell averages were calculated for comparisons of complex responses. Averages of the normalized data were calculated for each of the 10,322 points in each of the 206.44second traces (acquired at $50 \mathrm{~Hz}$ ), as well as the S.E. for those averages. These plots are therefore augmented versions of typical bar plots of peak currents (Supplemental Fig. 1) that additionally illustrate the differences in net charge, the kinetics of the responses, and the variability throughout the entire time course of the responses.

Data and Statistical Analysis. Comparisons of results (i.e., the calculated peak currents and net charge values for multiple replicates) were made using two-tailed unpaired $t$ tests between the data from two experiments, as indicated. A value of $P<0.05$ was used to constitute the level of significance, except as indicted when $P$ values were lower (Table 1). The statistics were calculated using an Excel template provided in Microsoft Office. As noted above, for some experiments the data also plotted as the point-by-point averages ( \pm S.E.M.) of all the replicates, permitting qualitative evaluation of the data by visual inspection.

\section{Results}

We used docking, MD simulations, and MMPBSA binding energy calculations for in silico screening of diEPP compounds that behaved as silent or partial agonists, as reported in the study by Quadri et al. (2016), to identify potential candidates for allosteric activators. Because there is no high-resolution structure of $\alpha 7$ available, we built a homology model of the ECD of the $\alpha 7 \mathrm{nAChR}$ based on the high-resolution crystal structure of the humanized chimeric ACh binding protein $(\alpha 7 \mathrm{AChBP})$ (Li et al., 2011), which has 64\% sequence identity to the $\alpha 7$ ECD. The $\alpha 7$ nAChR homology model was constructed without imposing fivefold symmetry, and the MD simulations that were run to refine the homology model enhanced the asymmetry. Considering the asymmetry of the $\mathrm{OA}$ sites and the past reports of binding sites in the vestibule of the receptor and its analog $\alpha 7$ AChBP (Spurny et al., 2015; Horenstein et al., 2016; Delbart et al., 2018; Quadri et al., 2019), we docked the ligands into all five interfaces of the receptor $\left(\mathrm{I}_{\mathrm{AB}}, \mathrm{I}_{\mathrm{BC}}, \mathrm{I}_{\mathrm{CD}}, \mathrm{I}_{\mathrm{DE}}, \mathrm{I}_{\mathrm{EA}}\right)$ with a grid large enough to cover the vestibular side to ensure that all possible binding sites and multiple subunit configurations were included in our analysis.

Docking of 16 diEPP derivatives (Supplemental Fig. 2) to the WT $\alpha 7$ ECD model showed ligand poses at the traditional OA site under the C-loop of the receptor and at another region formed by the vestibular loops of the neighboring receptor subunits (Fig. 2, top row). The base of this vestibular site was broadly formed by the loops between the residues 87-93 and 98-106, and the top part was formed by the residues 101-106 of the neighboring interface. Other residues contributing to the bottom of the cavity were F33, L56, Q57, M58, I90, and L91. This region observed for the diEPP derivatives is consistent with the putative AA site, as defined in our previous 


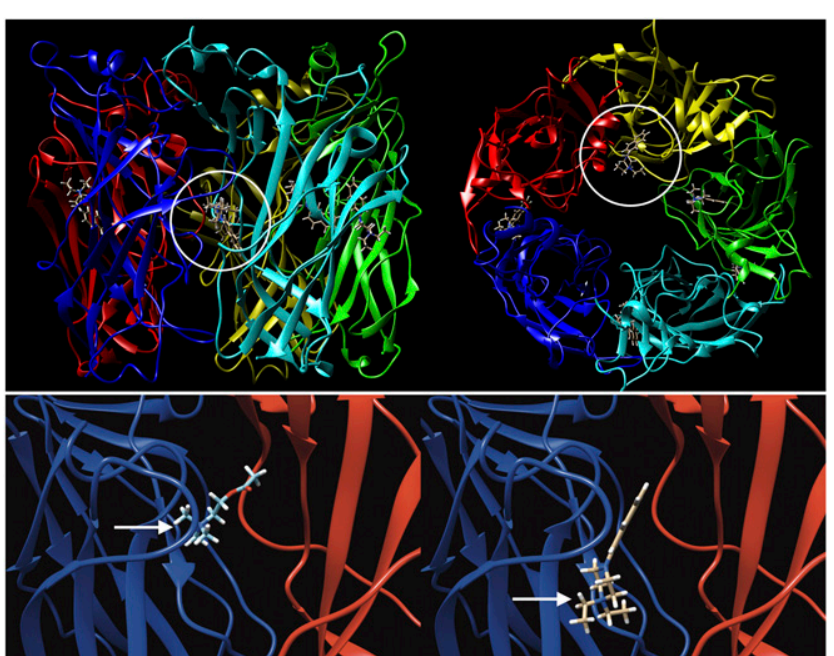

Fig. 2. (Top row) 2NDEP-bound $\alpha 7$ ECD homology models viewed from the side of the C-loop (left) and view from the top showing the vestibular AA site (right). The 2NDEP poses at the OA and the AA sites are circled in white. (Bottom row) Comparison of the ACh (left) and 2NDEP (right) OA site docking poses at the WT $\alpha 7$ ECD. Note the shift of the positively charged nitrogen in the 2NDEP pose marked with white arrows.

studies on allosteric activity of GAT107 and B-973 performed using the same $\alpha 7$ ECD model in this study (Quadri et al., 2019), and on allosteric activity of GAT107 performed with a different $\alpha 7$ model that had identified the residues defining this vestibular site as L56, M58, K87, I90, L92, F100, A102, Y118, P120, Y95, T103, R99, and D101 (Horenstein et al., 2016). Therefore, we refer to this vestibular site as the putative AA site throughout this work.

At the interface level, docking to the WT receptor model showed almost exclusively OA site poses for all 16 ligands at three interfaces $\left(\mathrm{I}_{\mathrm{AB}}, \mathrm{I}_{\mathrm{BC}}, \mathrm{I}_{\mathrm{EA}}\right)$, and, interestingly, a mixture of $\mathrm{OA}$ and/or AA site poses at two interfaces $\left(\mathrm{I}_{\mathrm{CD}}\right.$ and $\left.\mathrm{I}_{\mathrm{DE}}\right)$ (Supplemental Table 1). Of the 16 compounds analyzed, only 4 exclusively docked at both the $\mathrm{I}_{\mathrm{CD}}$ and $\mathrm{I}_{\mathrm{DE}} \mathrm{AA}$ sites, albeit with $1-7 \mathrm{kcal} / \mathrm{mol}$ weaker docking scores compared with their OA site poses (Supplemental Fig. 2, bottom row).

We used the best poses of the four diEPP compounds that exclusively preferred docking into the $\mathrm{AA}$ sites at $\mathrm{I}_{\mathrm{CD}}$ and $\mathrm{I}_{\mathrm{DE}}$ interfaces for MD simulations to allow interaction between the ligands and the protein, and sampled additional binding configurations. We also calculated MMPBSA (see Supplemental Material) for a more accurate comparison of ligand binding energies. 2NDEP (Fig. 1) particularly stood out among the other diEPP ligands for the following reasons: 1) 2NDEP molecules docked at the same two AA sites as GAT107 and both 2 NDEP molecules remained bound to the putative AA site for over 20 nanoseconds of MD simulation; 2) 2NDEP showed consistently low binding energies at both hypothetical AA sites (approximately $-11 \mathrm{kcal} / \mathrm{mol}$ ); and 3 ) at the OA site, control docking with ACh revealed that the position of the 2NDEP charged nitrogen was different than the position of the ACh charged nitrogen (Fig. 2, bottom row), and none of the final 2NDEP OA site binding configurations showed interactions with the hydrophobic pocket formed by L109 and L119, contrary to most diEPP ligands and ACh, which would be consistent with a difference in its mode of action. Based on these data, we chose 2NDEP as the likeliest candidate to act through the AA site, with lower OA site preference, and tested its activity experimentally compared with the ago-PAM GAT107.

In these experiments, our working model and assumptions were that: 1) $2 \mathrm{NDEP}$ was able to bind to the putative AA site, and 2) it would require a PAM to yield detectable channel activation. Thus, we wanted to use a compound known to inhibit AA, but it would be necessary to show that the blockade of any $2 \mathrm{NDEP}$ activity was occurring at the AA site, not the PAM site. For this purpose, we used 2,3,5,6MP-TQS (Fig. 1) to specifically block AA site activity of 2 NDEP.

The selectivity of 2,3,5,6MP-TQS for the AA site has been established in past studies (Gill et al., 2012; Horenstein et al., 2016). Note that the washout of GAT107 does not cause a total loss of PAM activity due to tight binding at the TMD PAM site of the $\alpha 7$ receptor (Papke et al., 2014). This phenomenon is called "primed potentiation." The inhibitory effect of $2,3,5,6 \mathrm{MP}-\mathrm{TQS}$ on AA but not primed potentiation has been used to substantiate the selectivity of its inhibitory effects at the AA site rather than the PAM site (Horenstein et al., 2016). In the experiments reported here, $300 \mu \mathrm{M} 2,3,5,6 \mathrm{MP}-$ TQS had a clear inhibitory effect on AA, but primed potentiation was not significantly affected, as could be expected from an AA site-selective antagonist. Therefore, we confirmed the previous observation that selective AA site inhibition by $2,3,5,6 \mathrm{MP}-\mathrm{TQS}$ was valid for our experimental conditions as well (Fig. 3A).

As a key experiment, we used 2,3,5,6MP-TQS to block the activation by $2 \mathrm{NDEP}$ and ACh potentiated by the type II PAM PNU-120596 (Hurst et al., 2005; Grønlien et al., 2007) to see whether 2 NDEP was affected more by the application of 2,3,5,6MP-TQS than were the ACh responses, as would be expected from an allosteric agonist. The $60 \mu \mathrm{M}$ ACh gave moderate activity when applied by itself, which was significantly enhanced by $30 \mu \mathrm{M}$ PNU-120596, peak currents increasing $11.1 \pm 3.6$-fold $(P<0.001)$ and a net charge $46.2 \pm$ 13.5-fold $(P<0.001)$. Coapplication of $300 \mu \mathrm{M} 2,3,5,6 \mathrm{MP}-$ TQS with $60 \mu \mathrm{M}$ ACh plus $30 \mu \mathrm{M}$ PNU-120596 resulted in a partial (60\%) inhibition of the PNU-120596-potentiated ACh response (Fig. 3B, left panel; Table 1). Next, we tested the effect of 2,3,5,6MP-TQS on 2NDEP activity. As expected from previous results (Quadri et al., 2016), the application of $30 \mu \mathrm{M} 2 \mathrm{NDEP}$ gave a weak partial agonist response when applied by itself, with peak currents and a net charge of $\leq 10 \%$ that of ACh applied alone. Coapplication of $30 \mu \mathrm{M}$ 2NDEP with $30 \mu \mathrm{M}$ PNU-120596 resulted in large potentiated responses (peak currents and net charge responses were $5.4 \pm 0.9$-fold and $10.8 \pm 3.2$-fold larger than ACh control subjects, respectively), which were almost completely abolished by $300 \mu \mathrm{M}$ 2,3,5,6MP-TQS (Fig. 3B, right panel; Table 1), in support of significant AA site involvement in 2NDEP activity. Note that the waveforms of these responses are the result of several complex underlying processes. In the examples shown in Fig. 3B, there are two or three ligands binding to multiple sites on each receptor. The receptors are distributed all over the surface of the oocyte, and drugs are being delivered in such a way that the concentration of each ligand increases and then decreases. In contrast to the $\mathrm{ACh} /$ PNU responses, the later peaks in the presence of $2 \mathrm{NDEP}$ are actually occurring as the drug concentrations are falling. 2NDEP is probably a channel blocker (as reported for other drugs in that series) (Quadri et al., 2016), and so the second peak is likely to represent relief of some of that channel block. 
A

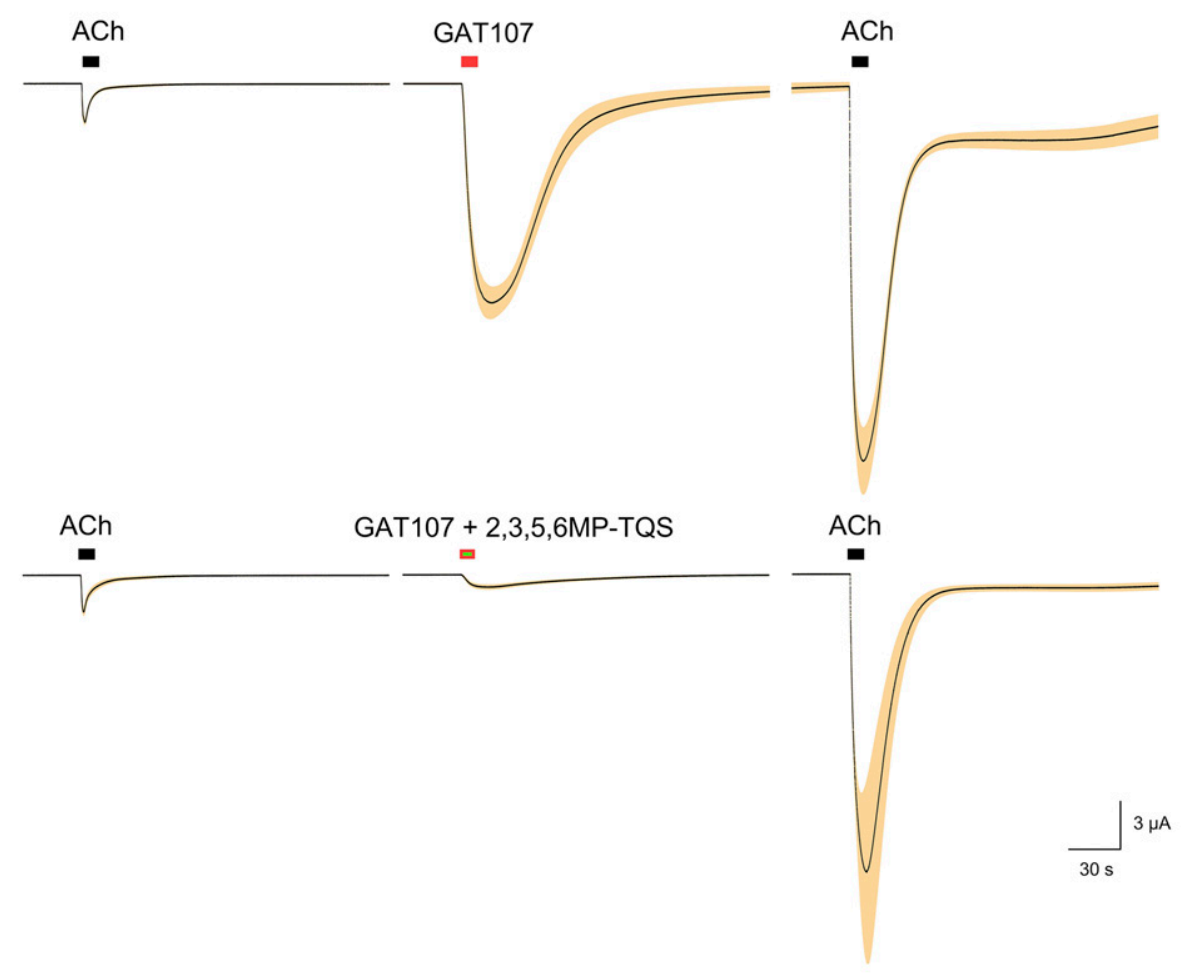

B

$60 \mu \mathrm{M} \mathrm{ACh}+30 \mathrm{PNU} \pm 300 \mu \mathrm{M} 2,3,5,6 \mathrm{MP}-\mathrm{TQS}$

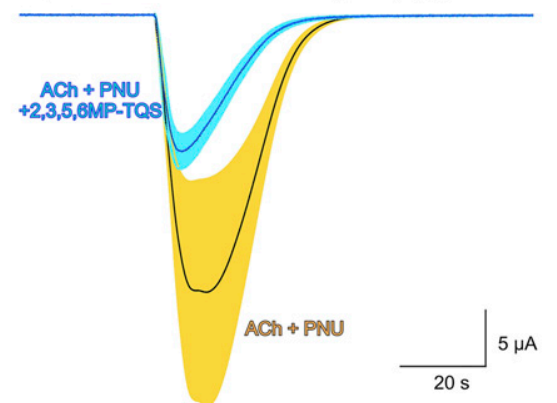

$30 \mu \mathrm{M} 2 \mathrm{NDEP}$ plus $30 \mu \mathrm{M} \mathrm{PNU} \pm 300 \mu \mathrm{M} 2,3,5,6 \mathrm{MP}-\mathrm{TQS}$

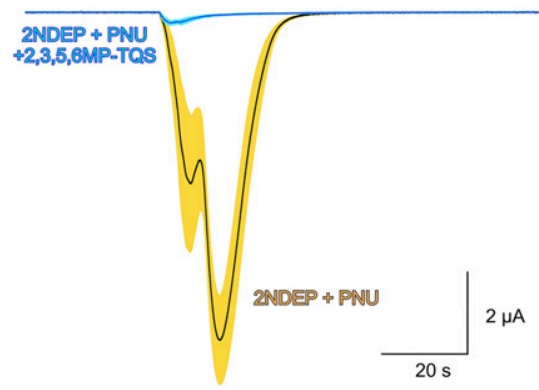

Fig. 3. (A) Inhibition of the $10 \mu \mathrm{M}$ GAT107 response on WT $\alpha 7 \mathrm{nAChR}$ by coapplication with $300 \mu \mathrm{M} 2,3,5,6 \mathrm{MP}-\mathrm{TQS}$ had little effect on the primed potentiation response. (Top trace) Responses to $60 \mu \mathrm{M}$ ACh, $10 \mu \mathrm{M}$ GAT107, and $60 \mu \mathrm{M}$ ACh on the same set of cells, with 12-second drug applications 3.5 minutes apart $(n=7)$. (Bottom trace) Responses to $60 \mu \mathrm{M}$ ACh, $10 \mu \mathrm{M}$ GAT107 plus $300 \mu \mathrm{M} 2,3,5,6 \mathrm{MP}-\mathrm{TQS}$, and $60 \mu \mathrm{M}$ ACh on the same set of cells, with 12 -second drug applications 3.5 minutes apart $(n=7)$. The black line is the average and gold bands are the S.E. (B, left panel) Activation of the WT $\alpha 7$ nAChR by $60 \mu \mathrm{M}$ ACh plus $30 \mu \mathrm{M}$ PNU-120596 $(n=8)$ (black lines with yellow error bands) and the effect of 300 $\mu \mathrm{M} 2,3,5,6 \mathrm{MP}-\mathrm{TQS}$ on potentiated response $(n=5)$ (blue lines with cyan error bands). (Right panel) Activation of the WT $\alpha 7 \mathrm{nAChR}$ by $30 \mu \mathrm{M} 2 \mathrm{NDEP}$ plus $30 \mu \mathrm{M}$ PNU-120596 ( $n=8$ ) (black lines with yellow error bands) and the effect of $300 \mu \mathrm{M} 2,3,5,6 \mathrm{MP}-\mathrm{TQS}$ on potentiated response $(n=8)$ (blue lines with cyan error bands). These averaged traces can be directly used to compare peak currents, as illustrated in Supplemental Fig. 1, and additionally convey the kinetic features of the responses and intrinsic variability over time. For details and statistics, see Table 1.

To further focus on the involvement of the AA site as a possible epitope for 2NDEP activity, we used a NOAR (Horenstein et al., 2016). NOARs are $\alpha 7$ nAChRs with mutations in the OA site, such that the receptors do not respond to $\mathrm{ACh}$ or other orthosteric agonists, but they can be allosterically activated by ago-PAMs such as GAT107. This provides a tool to discern whether a component of 2NDEP activity occurs independent of the OA site (Papke et al., 2014; Horenstein et al., 2016). Because the NOAR $\alpha 7 \mathrm{C} 190 \mathrm{~A}$ lacks the critical vicinal disulfide in the C-loop of the OA site, it cannot be activated by orthosteric ligands even when coupled with high concentrations of PNU-120596 (Fig. 4A). This allowed us to use $\alpha 7 \mathrm{C} 190 \mathrm{~A}$ to test whether
2NDEP could act as an allosteric agonist through the AA site of this mutant.

2NDEP did not activate the NOAR $\alpha 7 \mathrm{C} 190 \mathrm{~A}$ when applied by itself (our limit of detection is $10 \mathrm{nA}$ ), but coapplication of $100 \mu \mathrm{M} 2 \mathrm{NDEP}$ with $100 \mu \mathrm{M}$ PNU-120596 to $\alpha 7 \mathrm{C} 190 \mathrm{~A}$ evoked substantial responses (peak currents, $12.9 \pm 1.9 \mu \mathrm{A}$ ), which were significantly $(P<0.001)$ inhibited by the coapplication of $300 \mu \mathrm{M} 2,3,5,6 \mathrm{MP}-\mathrm{TQS}$ (Table 1), consistent with allosteric agonism of this molecule through the AA site (Fig. 4B). Note that for this mutant, the two peaks are still apparent in the potentiated responses, especially in the 2,3,5,6MPTQS-inhibited response, when both 2NDEP and the allosteric agonist are declining in concentration. 
A

\section{$\alpha 7 \mathrm{C} 190 \mathrm{~A}$}

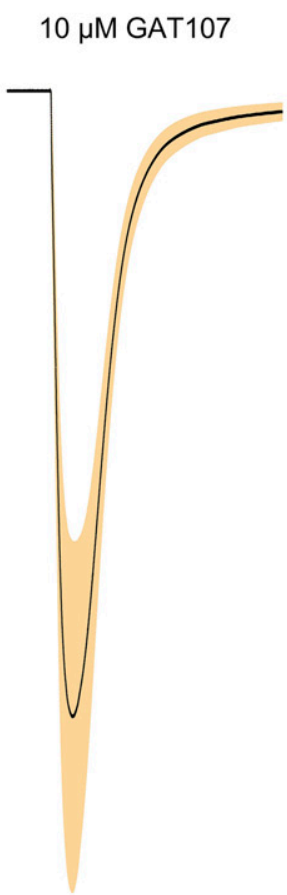

$100 \mu \mathrm{M}$ PNU-120596
$100 \mu \mathrm{M}$ PNU-120596

$+100 \mu \mathrm{M} \mathrm{ACh}$

B

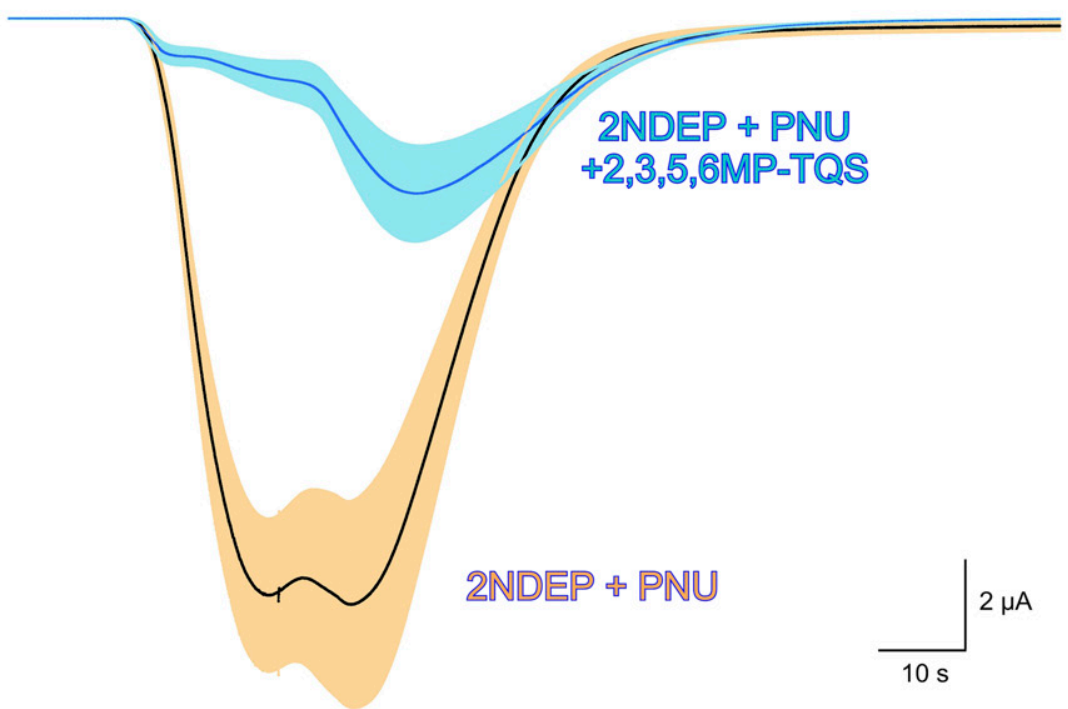

Fig. 4. (A) $\alpha 7 \mathrm{C} 190 \mathrm{~A}$ responses evoked by $10 \mu \mathrm{M}$ GAT107, $100 \mu \mathrm{M}$ PNU-120596, and $100 \mu \mathrm{M}$ PNU120596 plus $100 \mu \mathrm{M}$ ACh. (B) Activation of $\alpha 7 \mathrm{C} 190 \mathrm{~A}$ by $100 \mu \mathrm{M} 2 \mathrm{NDEP}$ plus $100 \mu \mathrm{M}$ PNU-120596 (black lines with yellow error bands, $n=5$ ), and $100 \mu \mathrm{M}$ 2NDEP plus $100 \mu \mathrm{M}$ PNU-120596 plus $300 \mu \mathrm{M}$ $2,3,5,6 \mathrm{MP}-\mathrm{TQS}$ (blue lines with cyan error bands, $n=$ 7). For details and statistics, see Table 1.

$60 \mathrm{~s}$
$4 \mu \mathrm{A}$
Based on the effectiveness of 2NDEP in activating $\alpha 7 \mathrm{C} 190 \mathrm{~A}$ when coapplied with PNU-120596, we tested other available diEPP derivatives with this mutant to find other potential allosterically active compounds (Fig. 5A). The results showed that $p-\mathrm{CF}_{3}$ diEPP, another compound that docked to AA sites at both the $\mathrm{I}_{\mathrm{CD}}$ and $\mathrm{I}_{\mathrm{DE}}$ interfaces of the WT receptor, could activate the $\alpha 7 \mathrm{C} 190 \mathrm{~A}$ mutant in a 2,3,5,6MP-TQS-sensitive manner at a level comparable to 2NDEP (Fig. 5B, left panel). However, $p-\mathrm{CF}_{3}$ diEPP behaved differently than $2 \mathrm{NDEP}$ in the WT $\alpha 7$ experiments. Contrary to $2 \mathrm{NDEP}$, $2,3,5,6 \mathrm{MP}-\mathrm{TQS}$-enhanced $p$ - $\mathrm{CF}_{3}$ diEPP potentiated activity in WT $\alpha 7$ experiments rather than diminishing it (Fig. 5B, right panel). These results suggest that $p-\mathrm{CF}_{3}$ diEPP prefers to bind to the OA site of the WT receptor, but in the absence of a functional OA site it can also couple with PAMs through the AA site, as evident in $\alpha 7 \mathrm{C} 190 \mathrm{~A}$ results.

To summarize, $2 \mathrm{NDEP}$ and $p-\mathrm{CF}_{3}$ diEPP, hypothesized to be allosterically active through our docking and binding energy calculations, were experimentally confirmed to be allosteric activators of the $\alpha 7$ receptor. 2NDEP or $p-\mathrm{CF}_{3}$ diEPP plus PNU-120596 showed potentiated responses at $\alpha 7 \mathrm{C} 190 \mathrm{~A}$, and 2,3,5,6MP-TQS, which targets the AA site, inhibited 


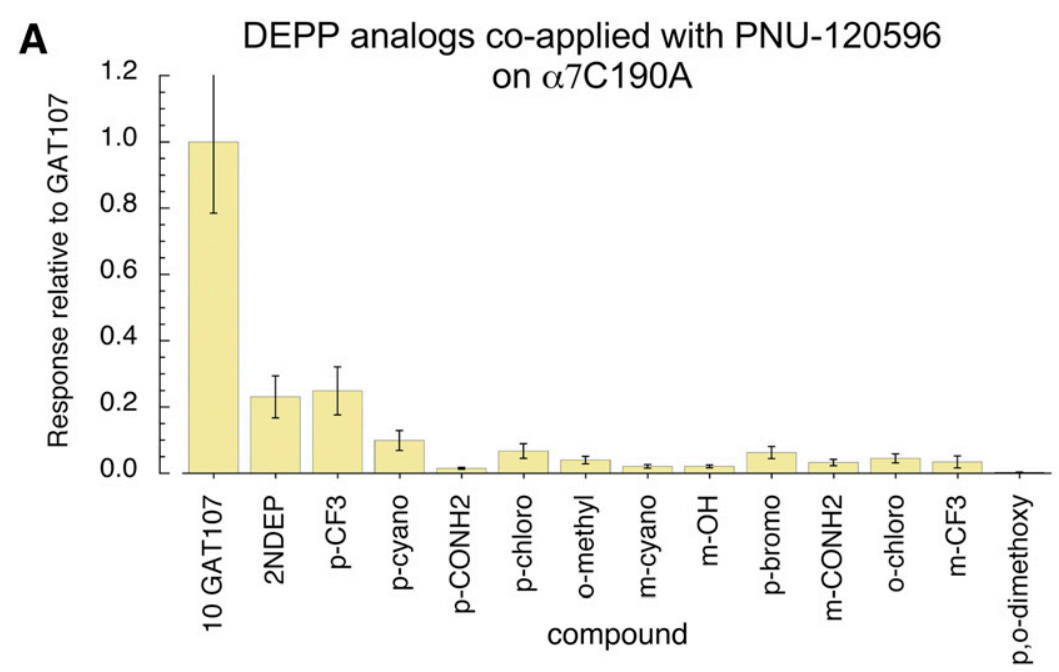

B
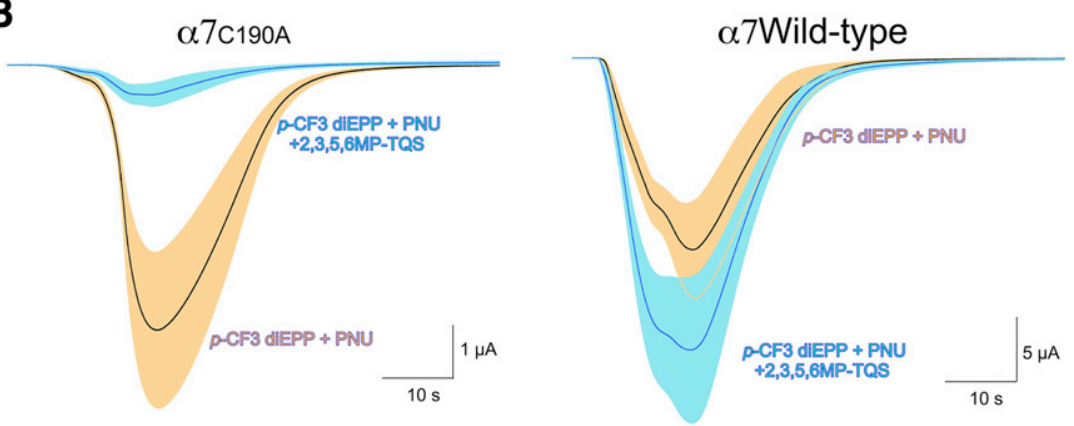

Fig. 5. (A) The effect of $100 \mu \mathrm{M}$ drug plus $100 \mu \mathrm{M}$ PNU120596 for diEPP derivatives on $\alpha 7 \mathrm{C} 190 \mathrm{~A}$ peak currents ( \pm S.D.), relative to $10 \mu \mathrm{M}$ GAT107 applications. All responses were significantly less than the GAT107 control responses $(P<0.001)$. (B, left panel) Activation of $\alpha 7 \mathrm{C} 190 \mathrm{~A}$ by $100 \mu \mathrm{M} p-\mathrm{CF}_{3}$ diEPP plus $100 \mu \mathrm{M}$ PNU-120596 (black lines with yellow error bands, $n=7$ ), and $100 \mu \mathrm{M} p-\mathrm{CF}_{3}$ diEPP plus $100 \mu \mathrm{M}$ PNU-120596 plus $300 \mu \mathrm{M} 2,3,5,6 \mathrm{MP}-\mathrm{TQS}$ (blue lines with cyan error bands, $n=7$ ). (Right panel) Activation of WT $\alpha 7$ by $100 \mu \mathrm{M} p-\mathrm{CF}_{3}$ diEPP plus $100 \mu \mathrm{M}$ PNU-120596 (black lines with yellow error bands, $n=8$ ), and $100 \mu \mathrm{M} p-\mathrm{CF}_{3}$ diEPP plus $100 \mu \mathrm{M}$ PNU-120596 plus $300 \mu \mathrm{M} 2,3,5,6 \mathrm{MP}-\mathrm{TQS}$ (blue lines with cyan error bands, $n=7$ ). For details and statistics, see Table 1 .
PNU-120596-potentiated 2NDEP and $p-\mathrm{CF}_{3}$ diEPP responses. However, the behavior of the two molecules were different at the WT receptor such that blocking the AA site with 2,3,5,6MP-TQS abolished 2NDEP activity while enhancing $p-\mathrm{CF}_{3}$ diEPP activity.

\section{Discussion}

The diEPP family of $\alpha 7$ ligands were originally designed based on the nonselective orthosteric ganglionic $\mathrm{nAChR}$ agonist dimethylphenylpiperazinium, and they have been shown to act as $\alpha 7$ antagonists, partial agonists, and silent agonists depending on the substitution of the phenyl ring or the nature of the charged group (Quadri et al., 2016, 2017; Horenstein and Papke, 2017). In the present work, we identified the allosteric agonism of a diEPP derivative, 2NDEP, formerly reported as a weak partial agonist of $\alpha 7 \mathrm{nAChR}$. PNU-120596-potentiated responses of 2 NDEP by the WT $\alpha 7$ were nearly abolished by the AA site-selective antagonist 2,3,5,6MP-TQS. 2NDEP could not activate the NOAR $\alpha 7 \mathrm{C} 190 \mathrm{~A}$ by itself, but it showed a robust potentiated response when coapplied with PNU-120596, which was also sensitive to $2,3,5,6 \mathrm{MP}-\mathrm{TQS}$.

Our homology model of the pentameric $\alpha 7$ ECD was not strictly fivefold symmetric, due to the differences in conformation between individual subunits, and the asymmetry was retained throughout the $\mathrm{MD}$ simulations. In addition to the asymmetry within the pentamer, an important finding was that the five potential OA sites of the $\alpha 7$ receptor are not equivalent. This nonequivalence was evident in the distribution of binding sites at the ECD and the differences in binding configuration of the ligands at the OA and putative AA sites of each interface (Supplemental Table 1). Asymmetry of the $\alpha 7$ receptor has been reported in past MD studies with the $\alpha 7$ receptor models that contain only ECD and both ECD and TMD domains (Henchman et al., 2003; Law et al., 2005; Chiodo et al., 2017; Quadri et al., 2019). Crystal structures of different $\alpha 7$ ligands with $\mathrm{AChBP}$ also reflect the variations in ligand binding configurations and $\mathrm{OA}$ site geometries. Different AChBP crystal structures cocrystallized with strychnine, GTS-21, or 4OH-GTS-21 show at least two distinct ligand binding configurations (Hibbs et al., 2009; Brams et al., 2011). Nonequivalent sites may be the result of stochastic fluctuations or they may be functionally significant. Heteromeric receptors have been shown to have nonorthodox binding sites at $\alpha / \alpha$ and $\beta / \alpha$ subunit interfaces that play regulatory roles (Wang and Lindstrom, 2018). By a similar logic, nonequivalence of the $\alpha 7$ subunit interfaces may play a role in the modulation of desensitization and the formation of allosteric or regulatory binding sites at the ECD of the receptor (Gulsevin, 2017). On the other hand, the identification of the exact role of this nonequivalence will require longer simulation times and extensive sampling of the protein conformations. But in the present study, we explored the various binding modes enabled by nonequivalent binding sites and interfaces.

The docking of GAT107 and 2,3,5,6MP-TQS to the WT $\alpha 7$ ECD model showed both the OA and AA site poses despite the lack of experimental evidence connecting the two molecules to the OA site (data not shown). These poses at the OA site may 
reflect weak ligand binding that would eventually lead to dissociation, or they may represent stable binding configurations with no functional importance since these molecules cannot form $\pi$-cation or electrostatic interactions with important aromatic cage residues such as W149, due to their lack of a permanent positive charge. Contrarily, the charged nitrogen of $2 \mathrm{NDEP}$ did form $\pi$-cation interactions with the aromatic cage, but the naphthalene functional group adopted multiple orientations at the interfaces, whereas the smaller acetyl group of $\mathrm{ACh}$ pointed toward the hydrophobic pocket inside the OA site formed by the residues L109 and L119.

The inhibitory effects of 2,3,5,6MP-TQS were predominantly at the AA site, but we also observed the inhibition of the PNU-120596-potentiated ACh responses of WT $\alpha 7$ (Fig. 3B, left panel). There are a couple of possibilities to explain this curiosity. One explanation is that $2,3,5,6 \mathrm{MP}-\mathrm{TQS}$ binds to the PAM binding site at the TMD of the receptor to nonspecifically block the potentiating effects of PNU-120596. This is possible, considering the structural similarity between 2,3,5,6MP-TQS and TQS-derivative PAMs, but the weak effect of $2,3,5,6 \mathrm{MP}-\mathrm{TQS}$ on primed potentiation by GAT107 after a washout period (Fig. 3A) suggests that a significant inhibition through the PAM binding site is unlikely or, under assay conditions, it was readily reversible. The failure of 2,3,5,6MP-TQS coapplication to inhibit WT $\alpha 7 p-\mathrm{CF}_{3}$ diEPP-potentiated responses (Fig. 5B, right panel) also disfavors the idea, as inhibition at the TMD PAM site would inhibit potentiated responses regardless of whether $p-\mathrm{CF}_{3}$ diEPP binds at the OA or AA site. Another possibility is that when 2,3,5,6MP-TQS is bound to the AA site, allosteric effects impact the baseline activity of ACh + PNU120596. Though it is beyond the scope of the present work to validate this hypothetical mechanism, the experimental results underscore the complexity of how multiple ligands impact receptor function.

2NDEP and $p-\mathrm{CF}_{3}$ diEPP both activated $\alpha 7 \mathrm{C} 190 \mathrm{~A}$ when coapplied with PNU-120596, but their preference for the AA site was different, as reflected by the 2,3,5,6MP-TQS experiments with the WT receptor. When applied alone, 2NDEP is a weak partial agonist of the $\alpha 7$ receptor, presumably through the OA site. Because 2,3,5,6MP-TQS application significantly diminishes 2 NDEP response in both WT and $\alpha 7 \mathrm{C} 190 \mathrm{~A}$ (Fig. 3B, right panel; Fig. 4B), we concluded that 2NDEP coupling with PAMs occurs more efficiently through the AA site, although coupling through the OA site cannot be entirely ruled out. Differently, $p-\mathrm{CF}_{3}$ diEPP is a typical silent agonist of the WT receptor that does not evoke a stand-alone response, yet it invokes large responses when coapplied with PNU120596. A possible explanation for the unaffected or possibly enhanced activity of $p-\mathrm{CF}_{3}$ diEPP when coapplied with 2,3,5,6MP-TQS is that the AA and OA sites have cross talk, such that a bound AA site results in enhanced coupling between PAMs and $p-\mathrm{CF}_{3}$ diEPP bound to the OA site.

Drawing conclusions regarding the exact mechanism of activation is a challenging task, and several limitations prevent us from drawing more specific conclusions. A simulation time of 20 nanoseconds is much shorter than the physiologic time scale for channel opening and transitions into states relevant for activity at the AA site, and the absence of the TMD and the intracellular domain of the receptor may reasonably be considered to impact the behavior of our ECD-only receptor model. Therefore, our models present a glimpse of only the early stages of ligand binding and receptor activation and/or desensitization. Despite these limitations, our in silico screening model that involved sampling of multiple binding sites and different binding site geometries has been successful in identifying candidate molecules for experimental screening.

Allosteric ligands of the $\alpha 7$ receptor have posed compelling targets for therapeutic purposes (Williams et al., 2011). Although ago-PAMs can activate the $\alpha 7 \mathrm{nAChR}$ allosterically, their mechanism of action includes the TMD PAM binding site (Gill et al., 2011; Papke et al., 2014). This new allosteric activity of 2 NDEP is noteworthy because it shows that transition of the receptor to the type II PAM-sensitive desensitization state can be achieved without a functional OA site, therefore opening the door to the development of drugs that target allosteric sites on the ECD of the $\alpha 7$ receptor with little or no activity at the OA site. Alternatively, $\alpha 7$ ligands that can bind to either OA or AA sites may show better therapeutic effect when coapplied with an AA site-selective antagonist.

In summary, we used docking, $\mathrm{MD}$, and binding energy calculations to predict ligands that target an allosteric binding site in the vestibule of the $\alpha 7$ ECD. These predictions were supported experimentally with voltage-clamp electrophysiology, and we thus identified 2NDEP as an allosteric agonist of the $\alpha 7 \mathrm{nAChR}$ that can activate the $\alpha 7$ NOAR C190A when coapplied with PNU-120596 in a 2,3,5,6MP-TQS-sensitive manner. Additionally, 2NDEP may serve as a lead for the future development of new ligands that could have activity in the CAP and therefore potential for therapeutic applications.

\section{Authorship Contributions}

Participated in research design: Gulsevin, Papke, Quadri, Horenstein.

Conducted experiments: Gulsevin, Stokes, Quadri.

Contributed new reagents or analytic tools: Gulsevin, Garai, Thakur, Quadri.

Performed data analysis: Gulsevin, Papke, Stokes.

Wrote or contributed to the writing of the manuscript: Gulsevin, Papke, Stokes, Quadri, Horenstein.

\section{References}

Brams M, Pandya A, Kuzmin D, van Elk R, Krijnen L, Yakel JL, Tsetlin V, Smit AB, and Ulens C (2011) A structural and mutagenic blueprint for molecular recognition of strychnine and d-tubocurarine by different cys-loop receptors. PLoS Biol 9: e1001034.

Case DA, Darden TA, Cheatham TE, Simmerling CL, Wang J, Duke RE, Luo R, Crowley M, Walker RC, Zhang W, et al. (2008) Amber 10, University of California, San Francisco, CA.

Chiodo L, Malliavin TE, Maragliano L, and Cottone G (2017) A possible desensitized state conformation of the human $\alpha 7$ nicotinic receptor: a molecular dynamics study. Biophys Chem 229:99-109.

Delbart F, Brams M, Gruss F, Noppen S, Peigneur S, Boland S, Chaltin P, BrandaoNeto J, von Delft F, Touw WG, et al. (2018) An allosteric binding site of the $\alpha 7$ nicotinic acetylcholine receptor revealed in a humanized acetylcholine-binding protein. J Biol Chem 293:2534-2545.

Friesner RA, Murphy RB, Repasky MP, Frye LL, Greenwood JR, Halgren TA, Sanschagrin PC, and Mainz DT (2006) Extra precision glide: docking and scoring incorporating a model of hydrophobic enclosure for protein-ligand complexes. J Med Chem 49:6177-6196.

Frisch MJ, Trucks GW, Schlegel HB, Scuseria GE, Robb MA, Cheeseman JR, Scalmani G, Barone V, Petersson GA, Nakatsuji H, et al. (2016) Gaussian 16, Gaussian, Wallingford, CT.

Gill JK, Dhankher P, Sheppard TD, Sher E, and Millar NS (2012) A series of $\alpha 7$ nicotinic acetylcholine receptor allosteric modulators with close chemical similarity but diverse pharmacological properties. Mol Pharmacol 81:710-718.

Gill JK, Savolainen M, Young GT, Zwart R, Sher E, and Millar NS (2011) Agonist activation of alpha7 nicotinic acetylcholine receptors via an allosteric transmembrane site. Proc Natl Acad Sci USA 108:5867-5872.

Gill-Thind JK, Dhankher P, D'Oyley JM, Sheppard TD, and Millar NS (2015) Structurally similar allosteric modulators of $\alpha 7$ nicotinic acetylcholine receptors exhibit five distinct pharmacological effects. J Biol Chem 290:3552-3562.

Grønlien JH, Håkerud M, Ween H, Thorin-Hagene K, Briggs CA, Gopalakrishnan M, and Malysz J (2007) Distinct profiles of alpha7 nAChR positive allosteric modulation revealed by structurally diverse chemotypes. Mol Pharmacol 72: $715-724$. 
Gulsevin A (2017) A Comparative Analysis of the Principles Behind $\alpha 7$ Nicotinic Acetylcholine Receptor Function, in Chemistry. Doctoral Dissertation, University of Florida, Gainesville, FL.

Halevi S, Yassin L, Eshel M, Sala F, Sala S, Criado M, and Treinin M (2003) Conservation within the RIC-3 gene family. Effectors of mammalian nicotinic acetylcholine receptor expression. J Biol Chem 278:34411-34417.

Henchman RH, Wang HL, Sine SM, Taylor P, and McCammon JA (2003) Asymmetric structural motions of the homomeric alpha7 nicotinic receptor ligand binding domain revealed by molecular dynamics simulation. Biophys $J$ 85:3007-3018.

Hibbs RE, Sulzenbacher G, Shi J, Talley TT, Conrod S, Kem WR, Taylor P, Marchot $\mathrm{P}$, and Bourne Y (2009) Structural determinants for interaction of partial agonists with acetylcholine binding protein and neuronal alpha7 nicotinic acetylcholine receptor. EMBO J 28:3040-3051.

Horenstein NA and Papke RL (2017) Anti-inflammatory silent agonists. ACS Med Chem Lett 8:989-991.

Horenstein NA, Papke RL, Kulkarni AR, Chaturbhuj GU, Stokes C, Manther K, and Thakur GA (2016) Critical molecular determinants of $\alpha 7$ nicotinic acetylcholine receptor allosteric activation: separation of direct allosteric activation and positive allosteric modulation. J Biol Chem 291:5049-5067.

Hurst RS, Hajós M, Raggenbass M, Wall TM, Higdon NR, Lawson JA, RutherfordRoot KL, Berkenpas MB, Hoffmann WE, Piotrowski DW, et al. (2005) A nove positive allosteric modulator of the alpha7 neuronal nicotinic acetylcholine receptor: in vitro and in vivo characterization. J Neurosci 25:4396-4405.

Jacobson MP, Friesner RA, Xiang Z, and Honig B (2002) On the role of the crystal environment in determining protein side-chain conformations. J Mol Biol $\mathbf{3 2 0}$ 597-608.

Kulkarni AR and Thakur GA (2013) Microwave-assisted expeditious and efficient synthesis of cyclopentene ring-fused tetrahydroquinoline derivatives using threecomponent povarov reaction. Tetrahedron Lett 54:6592-6595.

Law RJ, Henchman RH, and McCammon JA (2005) A gating mechanism proposed from a simulation of a human alpha7 nicotinic acetylcholine receptor. Proc Natl Acad Sci USA 102:6813-6818.

Li SX, Huang S, Bren N, Noridomi K, Dellisanti CD, Sine SM, and Chen L (2011) Ligand-binding domain of an $\alpha 7$-nicotinic receptor chimera and its complex with agonist. Nat Neurosci 14:1253-1259.

Papke RL (2014) Merging old and new perspectives on nicotinic acetylcholine receptors. Biochem Pharmacol 89:1-11.

Papke RL, Horenstein NA, Kulkarni AR, Stokes C, Corrie LW, Maeng CY, and Thakur GA (2014) The activity of GAT107, an allosteric activator and positive modulator of $\alpha 7$ nicotinic acetylcholine receptors (nAChR), is regulated by aromatic amino acids that span the subunit interface. J Biol Chem 289:4515-4531.

Papke RL and Porter Papke JK (2002) Comparative pharmacology of rat and human alpha7 nAChR conducted with net charge analysis. Br J Pharmacol 137:49-61.

Papke RL and Stokes C (2010) Working with OpusXpress: methods for high volume oocyte experiments. Methods 51:121-133.
Papke RL, Stokes C, Williams DK, Wang J, and Horenstein NA (2011) Cysteine accessibility analysis of the human alpha7 nicotinic acetylcholine receptor ligandbinding domain identifies L119 as a gatekeeper. Neuropharmacology 60:159-171.

Post-Munson DJ, Pieschl RL, Molski TF, Graef JD, Hendricson AW, Knox RJ, McDonald IM, Olson RE, Macor JE, Weed MR, et al. (2017) B-973, a novel piperazine positive allosteric modulator of the $\alpha 7$ nicotinic acetylcholine receptor. Eur $J$ Pharmacol 799:16-25.

Quadri M, Garai S, Thakur GA, Stokes C, Gulsevin A, Horenstein NA, and Papke RL (2019) Macroscopic and microscopic activation of $\alpha 7$ nicotinic acetylcholine receptors by the structurally unrelated allosteric agonist-positive allosteric modulators (ago-PAMs) B-973B and GAT107. Mol Pharmacol 95:43-61.

Quadri M, Papke RL, and Horenstein NA (2016) Dissection of N,N-diethyl-N'-phenylpiperazines as $\alpha 7$ nicotinic receptor silent agonists. Bioorg Med Chem 24 286-293.

Quadri M, Stokes C, Gulsevin A, Felts ACJ, Abboud KA, Papke RL, and Horenstein NA (2017) Sulfonium as a surrogate for ammonium: a new $\alpha 7$ nicotinic acetylcholine receptor partial agonist with desensitizing activity. J Med Chem 60 7928-7934.

Spurny R, Debaveye S, Farinha A, Veys K, Vos AM, Gossas T, Atack J, Bertrand S, Bertrand D, Danielson UH, et al. (2015) Molecular blueprint of allosteric binding sites in a homologue of the agonist-binding domain of the $\alpha 7$ nicotinic acetylcholine receptor. Proc Natl Acad Sci USA 112:E2543-E2552.

Thakur GA, Kulkarni AR, Deschamps JR, and Papke RL (2013) Expeditious synthesis, enantiomeric resolution, and enantiomer functional characterization of (4 (4-bromophenyl)-3a,4,5,9b-tetrahydro-3H-cyclopenta[c]quinoline-8-sulfonamide (4BP-TQS): an allosteric agonist-positive allosteric modulator of $\alpha 7$ nicotinic acetylcholine receptors. J Med Chem 56:8943-8947.

Wang J and Lindstrom J (2018) Orthosteric and allosteric potentiation of heteromeric neuronal nicotinic acetylcholine receptors. Br J Pharmacol 175:1805-1821.

Wang J, Wang W, Kollman PA, and Case DA (2006) Automatic atom type and bond type perception in molecular mechanical calculations. J Mol Graph Model 25: 247-260.

Wang J, Wolf RM, Caldwell JW, Kollman PA, and Case DA (2004) Development and testing of a general amber force field. J Comput Chem 25:1157-1174.

Williams DK, Wang J, and Papke RL (2011) Positive allosteric modulators as an approach to nicotinic acetylcholine receptor-targeted therapeutics: advantages and limitations. Biochem Pharmacol 82:915-930.

Address correspondence to: Nicole A. Horenstein, Department of Chemistry, University of Florida, P.O. Box 117200, Gainesville, FL 32611-7200. E-mail: horen@chem.ufl.edu; or Roger L. Papke, Department of Pharmacology and Therapeutics, University of Florida, P.O. Box 100267, Gainesville, FL, 32610-0267. E-mail: rlpapke@ufl.edu 